\title{
Control-relevant modeling and simulation of a SOFC-GT hybrid system $^{\mathrm{a}}$
}

\author{
RAMBABU KANDEPU* ${ }^{*}$, LARS IMSLAND 9 , CHRISTOPH \\ STILLER $\ddagger$, BJARNE A. FOSS $\dagger$ and VINAY KARIWALA
}

Keywords: SOFC, GT, control relevant, fuel cells, modeling, PI controller.

In this paper, control-relevant models of the most important components in a SOFC-GT hybrid system are described. Dynamic simulations are performed on the overall hybrid system. The model is used to develop a simple control structure, but the simulations show that more elaborate control is needed.

\section{Introduction}

Solid Oxide Fuel Cells (SOFC) integrated in Gas Turbine (GT) cycles (often denoted as hybrid systems) is a promising concept for production of efficient and low-polluting electrical power. The SOFC can produce electric power at an electrical efficiency of about $55 \%$, and when it is combined with a GT, studies show that the net electrical efficiency can be increased up to 70\% Pålsson et al. (2000). The hybrid system uses natural gas as fuel and the percentage of pollutant flue gases is low compared to conventional power production from fossil fuels.

Due to the tight integration between the SOFC and the GT in a hybrid system, dynamic operability (and hence control) of the process is a challenge. It is important not only to design a good control system, but also to choose a process design that together with the appropriate control structure allows satisfying disturbance rejection and part load operation. Such a design procedure is usually called an integrated process design, see eg. van Schijndel \& Pistikopoulos (1999). To be able to design control structures and analyze dynamic behavior, it is very beneficial to have low complexity models of the components of the hybrid system. Such models are also valuable for online optimization. The aim of this article is to develop a low complexity hybrid system model which includes the relevant dynamics for controllability analysis and control design.

The paper is outlined as follows: The models of the components of the hybrid system are described. Dynamic simulations and the motivation for developing a control system is presented. The control structure and simulation results with the control structure are reported. A nomenclature can be found at the end of the paper.

Corresponding author.

†Department of Engineering Cybernetics, Norwegian University of Science and Technology 7491 Trondheim, Norway. \{Rambabu.Kandepu, Bjarne.A.Foss\}@itk.ntnu.no

\$Department of Process Engineering, Norwegian University of Science and Technology 7491

Trondheim, Norway. Christoph.Stiller@ntnu.no

$\S$ Department of Chemical Engineering, Norwegian University of Science and Technology 7491 Trondheim, Norway. kariwala@chemeng.ntnu.no

JSINTEF ICT, 7465, Trondheim, Norway. Lars.Imsland@sintef.no

aAn early version of this paper was presented at SIMS 2005, the 46th Conference on Simulation and Modeling, Trondheim, Norway, October 13-14, 2005. 


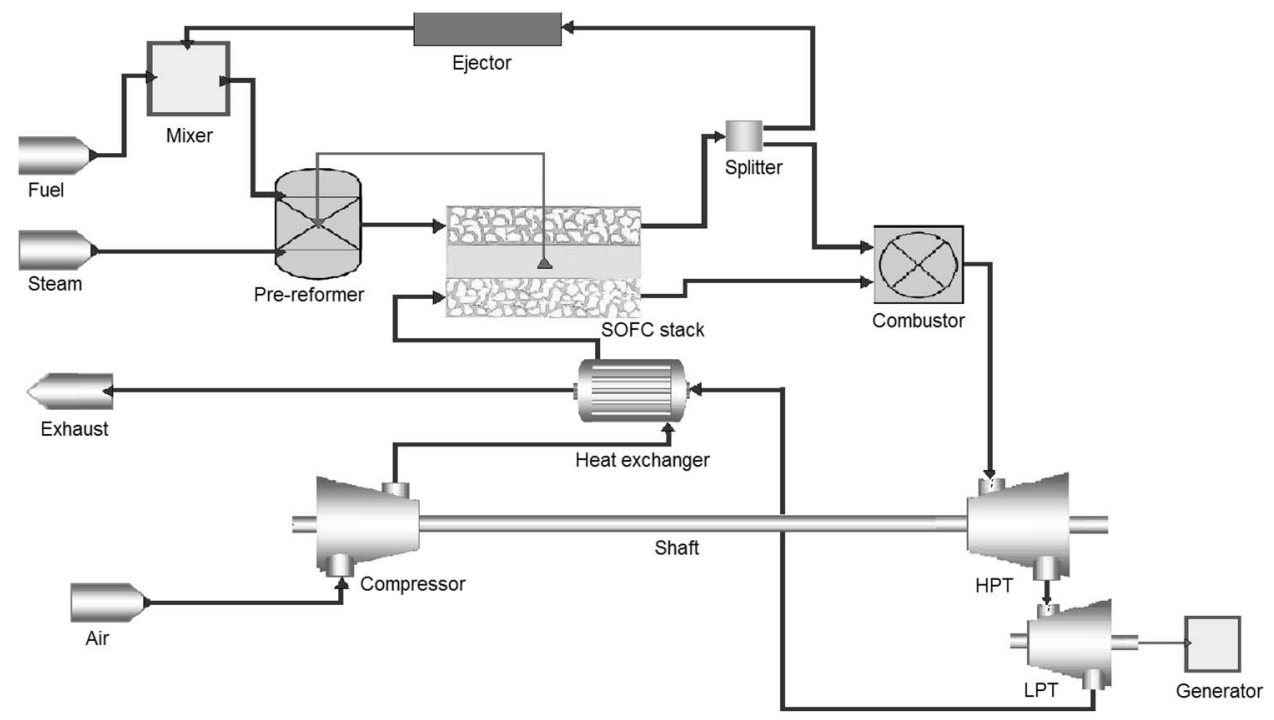

Figure 1. Hybrid system: double shaft configuration.

\section{Process description}

The hybrid system using a double shaft GT configuration (one gas turbine connected to a compressor and one power turbine connected to a generator) is shown in Figure 1. In the hybrid system the SOFC stack is coupled with a compressor-turbine setup. Methane is used as the fuel. It is mixed with a part of anode flue gas and is supplied to a pre-reformer. A part of the methane is steam reformed and hydrogen is generated. The remaining part of the methane is reformed in the anode volume of the SOFC. As the steam reformation is endothermic heat must be supplied. The pre-reformer receives radiation heat from the SOFC stack. The gas mixture from the pre-reformer goes to the anode volume of the SOFC. Air from atmosphere is compressed and heated in a recuperative heat exchanger before it goes to the cathode volume of the SOFC. Electrochemical reactions take place in the SOFC and voltage is developed across the cell. The rate of the electrochemical reactions depend on the current. A part of the anode flue gas is recycled to supply steam to the pre-reformer. The remaining part of the anode flue gas and cathode flue gas are supplied to a combustion chamber where the unused fuel is burnt. The combusted gas mixture is then expanded in a high pressure turbine (HPT) with variable shaft speed, which supplies the power needed by the compressor. The HPT flue gas is then expanded to atmospheric pressure in a low pressure turbine (LPT) with constant shaft speed, which is coupled to a generator producing AC electric power. The expanded gas mixture is used to heat up the compressed air in the heat exchanger.

\section{Modeling}

All the components of the hybrid system are modeled in the modular modeling environment gPROMS (2004). In a material stream from/to any component in the hybrid system, the following components can be present; Nitrogen $\left(\mathrm{N}_{2}\right)$, Oxygen $\left(\mathrm{O}_{2}\right)$, Hydrogen $\left(\mathrm{H}_{2}\right)$, Methane $\left(\mathrm{CH}_{4}\right)$, Steam $\left(\mathrm{H}_{2} \mathrm{O}\right)$, Carbonmonoxide $(\mathrm{CO})$, and Carbondioxide $\left(\mathrm{CO}_{2}\right)$. A number is assigned to each of these components to simplify the notation: 


\begin{tabular}{|l|ccccccc|}
\hline$i$ & 1 & 2 & 3 & 4 & 5 & 6 & 7 \\
\hline comp. & $\mathrm{N}_{2}$ & $\mathrm{O}_{2}$ & $\mathrm{H}_{2}$ & $\mathrm{CH}_{4}$ & $\mathrm{H}_{2} \mathrm{O}$ & $\mathrm{CO}$ & $\mathrm{CO}_{2}$ \\
\hline
\end{tabular}

Table 1. Reactions at anode and cathode

\begin{tabular}{ll}
\hline At anode & \\
Reaction & Reaction rate $\left(r_{j}^{a n}\right)$ \\
\hline $\mathrm{H}_{2}+\mathrm{O}^{2-} \rightarrow \mathrm{H}_{2} \mathrm{O}+2 e^{-}$ & $r_{1}^{a n}$ \\
$\mathrm{CH}_{4}+\mathrm{H}_{2} \mathrm{O} \Leftrightarrow \mathrm{CO}+3 \mathrm{H}_{2}$ & $r_{2}^{a n}$ \\
$\mathrm{CO}+\mathrm{H}_{2} \mathrm{O} \Leftrightarrow \mathrm{CO}_{2}+\mathrm{H}_{2}$ & $r_{3}^{a n}$ \\
$\mathrm{CH} \mathrm{H}_{4}+2 \mathrm{H}_{2} \mathrm{O} \Leftrightarrow \mathrm{CO}_{2}+4 \mathrm{H}_{2}$ & $r_{4}^{a n}$ \\
At cathode & \\
Reaction & Reaction rate $\left(r_{j}^{a n}\right)$ \\
$\frac{1}{2} \mathrm{O}_{2}+2 e^{-} \rightarrow \mathrm{O}^{2-}$ & $r_{1}^{c a}$ \\
\hline
\end{tabular}

\subsection{SOFC stack}

There are several dynamic, distributed SOFC models reported in the literature. For example, Achenbach (1994) developed a three dimensional, dynamic, distributed model for a planar SOFC stack. Chan et al. (2003), Chan et al. (2002), Thorud et al. (2004), Stiller et al. (2005) and Magistri et al. (2004) all developed distributed, dynamic tubular SOFC models for designs similar to that of Siemens Westinghouse, for use in hybrid systems.

The SOFC is a device which converts chemical energy of a fuel directly into electrical energy. The basic components of the SOFC are anode, cathode and electrolyte. Fuel is supplied to the anode and air is supplied to the cathode. At the cathodeelectrolyte interface, oxygen molecules accept electrons coming from the external circuit to form oxide ions; see Table 1 for reactions. The electrolyte layer allows only oxide ions to pass through and at the anode-electrolyte interface, hydrogen molecules present in the fuel react with oxide ions to form steam and electrons get released. These electrons pass through the external circuit and reach the cathode-electrolyte layer, and thus the circuit is closed. Table 1 gives the list of reactions that take place at anode and cathode and the corresponding reaction rates notation.

In practice, a number of cells are connected either in series or in parallel or in both ways according to voltage requirement and the number of cells in the stack depends on the power demand. In this paper, we assume that all the SOFCs in the SOFC stack operate at identical conditions. In addition, the following main assumptions have been made in developing the model.

1. All the physical variables are assumed to be uniform over the SOFC, resulting in a lumped model.

2. There is sufficient turbulence and diffusion within the anode and the cathode for perfect mixing to occur (CSTR).

3. The gas temperatures within the SOFC are assumed to be the same as the solid; i.e. the thermal inertia of the gases is neglected.

4. For the energy balance, pressure changes within the SOFC are neglected.

5. All gases are assumed to be ideal. 
The dynamic model of a single SOFC is developed using two mass balances; one for anode volume and the other for cathode volume, and one overall energy balance. The two mass balances are;

$$
\begin{gathered}
\frac{d N_{i}^{a n}}{d t}=\dot{N}_{i}^{i n, a n}-\dot{N}_{i}^{o u t, a n}+\sum_{j=1}^{n_{r x}^{a n}} a_{i j}^{a n} r_{j}^{a n}, i=1, \ldots, 7, n_{r x}^{a n}=4 \\
\frac{d N_{i}^{c a}}{d t}=\dot{N}_{i}^{i n, c a}-\dot{N}_{i}^{\text {out }, c a}+\sum_{j=1}^{n_{r x}^{c a}} a_{i j}^{c a} r_{j}^{c a}, i=1, \ldots, 7, n_{r x}^{c a}=1
\end{gathered}
$$

The reaction rates corresponding to the electrochemical reactions $\left(r_{1}^{c a}, r_{1}^{a n}\right)$ are directly related by the current,

$$
r_{1}^{a n}=I /(2 F)=r_{1}^{c a}
$$

and the reaction rates corresponding to the reforming reactions are calculated as proposed by Xu \& Froment (1989). It is assumed that the exhaust flows at the anode and cathode outlets can be described by the choked exhaust flow equation. This means that the mass flow rate of the exhaust flow at the anode (cathode) depends on the pressure difference between the pressure inside the anode (cathode) and the pressure at the outlet Padulles et al. (2000):

$$
\begin{aligned}
& \dot{m}_{\text {out }, \text { an }}=\sqrt{k_{\text {an }}\left(p_{\text {an }}-p_{\text {out }, a n}\right)} \\
& \dot{m}_{\text {out }, c a}=\sqrt{k_{c a}\left(p_{c a}-p_{\text {out }, c a}\right)}
\end{aligned}
$$

The partial pressures, volume, and temperature are assumed to be related by the ideal gas equation, for instance at the anode,

$$
p_{i}^{a n} V_{a n}=N_{i}^{a n} R T
$$

The energy balance accounts for the whole SOFC volume, and is given by Thomas (1999), Lukas et al. (2001):

$$
C^{S} \frac{d T}{d t}=\sum_{i=1}^{N} \dot{N}_{i}^{i n, a n}\left(\Delta \bar{h}_{i}^{i n, a n}-\Delta \bar{h}_{i}\right)+\sum_{i=1}^{N}\left(\dot{N}_{i}^{i n, c a}\left(\Delta \bar{h}_{i}^{i n, c a}-\Delta \bar{h}_{i}\right)-\sum_{j=1}^{M} \Delta \bar{h}_{j}^{r x} r_{j}^{a n}-P_{D C}-P_{r a d}\right.
$$

In this equation, the temperature changes of gases are neglected as they are fast compared to the temperature changes of the solid and by assuming that these fast changes of gas temperatures do not influence the dynamics of the overall process. Hence the energy balance gives a dynamic equation for the temperature changes of the SOFC solid.

In (6), $P_{D C}$ represents the amount of DC power produced by the SOFC and $P_{\text {rad }}$ represents the amount of radiation heat given from the SOFC. As the SOFC operating temperature is higher than that of the surroundings, there is always some loss due to radiation.

The operating cell voltage is given by

$$
V=E^{O C V}-V_{l o s s}
$$


where the open circuit voltage of the cell is given by the Nernst equation Larminie \& Dicks (2003),

$$
E^{O C V}=E^{o}+\frac{R T}{2 F} \ln \left(\frac{p_{H_{2}}^{a n} p_{O_{2}}^{a n}{ }^{0.5}}{p_{H_{2} \mathrm{O}}^{a n}}\right)
$$

where $E^{o}$ is the EMF at standard pressure. $V_{\text {loss }}$ is the voltage loss calculated by a semi-emperical function in terms of current and temperature.

Air Utilization (AU) and Fuel Utilization (FU) are defined as

$$
\begin{aligned}
& \mathrm{AU}=1-\frac{\dot{N}_{O_{2}}^{\text {out }}}{\dot{N}_{O_{2}}^{\text {in }}} \\
& \mathrm{FU}=1-\frac{\dot{N}_{H_{2}}^{\text {out }}}{\dot{N}_{H_{2}}^{\text {in }}}
\end{aligned}
$$

Recycle ratio is defined as the ratio of the fuel flow recycled to the fuel flow at the anode outlet.

The developed low complexity SOFC model is evaluated against a detailed model Thorud et al. (2004), Stiller et al. (2005). The conclusion is that the low complexity model is good enough to approximate important dynamics of the SOFC and can be used for operability and control studies Kandepu et al. (2005).

\subsection{Reformer}

A reformer is used to convert methane into hydrogen by steam reforming. It is a fixed volume reactor having two inlets; one for methane and the other for steam and one outlet. Three reformation reactions are considered which are given in Table 1. The reformation is a highly endothermic process, so heat must to be supplied to the reactor. As the SOFC operates at a high temperature, there is radiation from the SOFC stack and this can be supplied to the reformer by using a suitable mechanical design Thorud et al. (2004). The operating temperature of the reactor is in the range $500^{\circ} \mathrm{C}-700^{\circ} \mathrm{C}$. The following assumptions were made:

1. The model is lumped. In practice, a reformer reactor is a tubular reactor $\mathrm{Xu} \&$ Froment (1989). Hence all the variables are distributed. However, all variables are assumed to be uniform over the reactor volume.

2. There is sufficient turbulence and diffusion within the reactor for perfect mixing to occur.

3. The pressure losses are neglected within the reactor.

4. All gases are assumed to obey the ideal gas equation within the reactor volume.

The dynamic mode is developed by using one mass balance and one energy balance for the reformer. The mass balance equation is

$$
\frac{d N_{i}}{d t}=\dot{N}_{i}^{\text {in,fuel }}+\dot{N}_{i}^{\text {in,steam }}-\dot{N}_{i}^{\text {out }}+\sum_{j=1}^{n_{r x}} a_{i j} r_{j}, i=1 \ldots 7, n_{r x}=3
$$

where $r_{j}$, the reaction rates are calculated as proposed by $\mathrm{Xu} \&$ Froment (1989). The energy balance is given by 


$$
\begin{aligned}
C^{S} \frac{d T}{d t} & =\sum_{i=1}^{N}\left(\dot{N}_{i}^{\text {in.fuel }}\left(\Delta \bar{h}_{i}^{\text {in,fuel }}-\Delta \bar{h}_{i}\right)\right. \\
& +\sum_{i=1}^{N}\left(\dot{N}_{i}^{\text {in,steam }}\left(\Delta \bar{h}_{i}^{\text {in,steam }}-\Delta \bar{h}_{i}\right)-\sum_{j=1}^{M} \Delta \bar{h}_{j}^{r x} r_{j}+P_{\text {heat }}, \quad N=7, M=3\right.
\end{aligned}
$$

where $P_{\text {heat }}$ represents the amount of heat power supplied to the reactor.

\subsection{Heat exchanger}

A very simple model of a counter-flow heat exchanger is used, in which the amount of the heat exchanged depends on the heat transfer coefficient of the exchanger wall and also the average temperature difference between the hot and cold streams. A first order time delay is introduced to temperatures of both streams.

The following assumptions were made in the model,

1. The model is lumped. All the physical parameters are assumed to be uniform over the heat exchanger.

2. There is no pressure loss within the heat exchanger.

\subsection{Combustion chamber}

The combustion chamber has $n_{\text {in }}$ inlet streams and one outlet stream. It burns the fuel coming from all the inlet flows in the presence of oxygen. The requirement is that enough oxygen should be supplied to the combustor. In this model, the fuel can be methane, hydrogen or carbonmonoxide or a mixture of these fuels.

The following reactions are being considered during the combustion.

$$
\begin{aligned}
2 \mathrm{H}_{2}+\mathrm{O}_{2} & \rightarrow 2 \mathrm{H}_{2} \mathrm{O} \\
\mathrm{CH}_{4}+2 \mathrm{O}_{2} & \rightarrow 2 \mathrm{H}_{2} \mathrm{O}+\mathrm{CO}_{2} \\
2 \mathrm{CO}+\mathrm{O}_{2} & \rightarrow 2 \mathrm{CO}_{2}
\end{aligned}
$$

The following are the assumptions made in the combustor model.

1. The pressure of all the inlet flows is the same.

2. As the combustion process is very rapid, it is modeled as an instantaneous process. Also complete combustion is assumed.

3. The model is a bulk model; all the physical variables are assumed to be uniform over the combustion chamber.

4. There is a $2 \%$ pressure loss in combustor volume.

A mass and energy balance for the whole control volume is used:

$$
\begin{gathered}
\sum_{k=1}^{n_{i n}} \dot{N}_{i}^{i n, k}+\sum_{j=1}^{n_{r x}} a_{i j} r_{j}=\dot{N}_{i}^{\text {out }}, i=1 \ldots 7, n_{r x}=3 \\
\sum_{k=1}^{n_{i n}} \sum_{i=1}^{N}\left(\dot{N}_{i}^{i n, k} \Delta \bar{h}_{i}^{i n, k}\right)-\sum_{i=1}^{N}\left(\dot{N}_{i}^{i n} \Delta \bar{h}_{i}\right)-\sum_{j=1}^{M} \Delta \bar{h}_{j}^{r x} r j=0, \quad N=7, M=3
\end{gathered}
$$

where $n_{\text {in }}$ represents the number of inlets. 


\subsection{Gas turbine}

Compressor and turbine models are based on steady state performance map characteristics Stiller et al. (2005). The map is modeled using polynomials of 4th and 5th order for reduced mass flow, pressure and efficiency as functions of reduced shaft speed and operation line. The following are the assumption made in both the compressor and turbine models:

1. The model assumes constant isentropic efficiency.

2. The working fluid is assumed to satisfy the ideal gas equation.

A shaft model accounts for the dynamics of the rotating mass in the gas turbine system which is modeled by using the equation,

$$
\dot{\omega}=P_{b} /(I \omega)
$$

where $P_{b}$ is the power balance across the shaft, $I$ is the moment of inertia of the rotating mass and $\omega$ is the angular velocity of the shaft.

\section{Simulation}

Nominal values of the states for the hybrid system are given in Table 2. In the SOFC stack there are 1160 single cells. The fuel mass flow rate is varied in the simulations to study the hybrid system dynamics.

The fuel flow rate is changed in steps at different time instants and the details are given in Table 3. During the simulation, FU is kept constant at 0.85 , here it is assumed

Table 2. Nominal states of the hybrid system

\begin{tabular}{ll}
\hline Variable & \multicolumn{1}{c}{ Value } \\
\hline current & $255 \mathrm{~A}$ \\
fuel flow rate & $0.007 \mathrm{~kg} / \mathrm{s}$ \\
SOFC temperature & $1203 \mathrm{~K}$ \\
TIT & $1305 \mathrm{~K}$ \\
cathode inlet temperature & $1068 \mathrm{~K}$ \\
exhaust temperature & $502 \mathrm{~K}$ \\
voltage & $0.74 \mathrm{~V}$ \\
SOFC stack power & $219 \mathrm{~kW}$ \\
generator power & $70 \mathrm{~kW}$ \\
air mass flow rate & $0.426 \mathrm{~kg} / \mathrm{s}$ \\
HPT shaft speed & $68,588 \mathrm{rpm}$ \\
AU & $25 \%$ \\
FU & $85 \%$ \\
recycle ratio & 0.54 \\
reforming degree & $29 \%$ \\
steam/methane ratio & 2 \\
\hline
\end{tabular}

Table 3. Simulation details for fuel flow changes

\begin{tabular}{ll}
\hline Time & \multicolumn{1}{c}{ Change } \\
\hline 100 & fuel flow rate is decreased by $20 \%$ \\
200 & fuel flow rate is increased back to $100 \%$ \\
300 & fuel flow rate is increased by $20 \%$ \\
400 & fuel flow rate is decreased back to $100 \%$ \\
\hline
\end{tabular}


that FU can be estimated using a perfect observer. The changes in the fuel flow rate effect important system variables and the effect is explained below.

The simulated temperature and power profiles are shown in Figure 3 and voltage and air utilization (AU) profiles are shown in Figure 4. When fuel flow rate is decreased by $20 \%$ at constant FU and the current drawn from SOFC is decreased. Since the electrochemical reaction rate is decreased, the amount of heat generated from electrochemical reactions is decreased. This makes the SOFC temperature and voltage to decrease. As both the current and voltage are decreased at the new steady state, so is the SOFC stack power. As the fuel flow is decreased, the amount of unused fuel to the combustor decreases, hence Turbine Inlet Temperature (TIT) is decreased. This would decrease the power generated from LPT. As both the stack power and power from LPT are decreased the total power from the hybrid system is decreased.

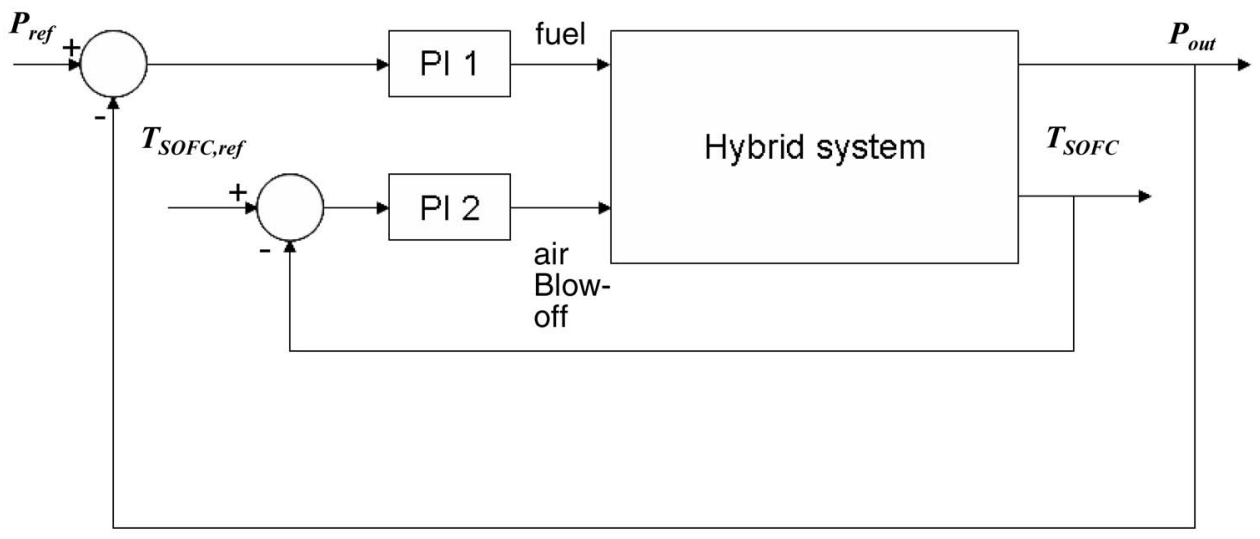

Figure 2. Control structure.
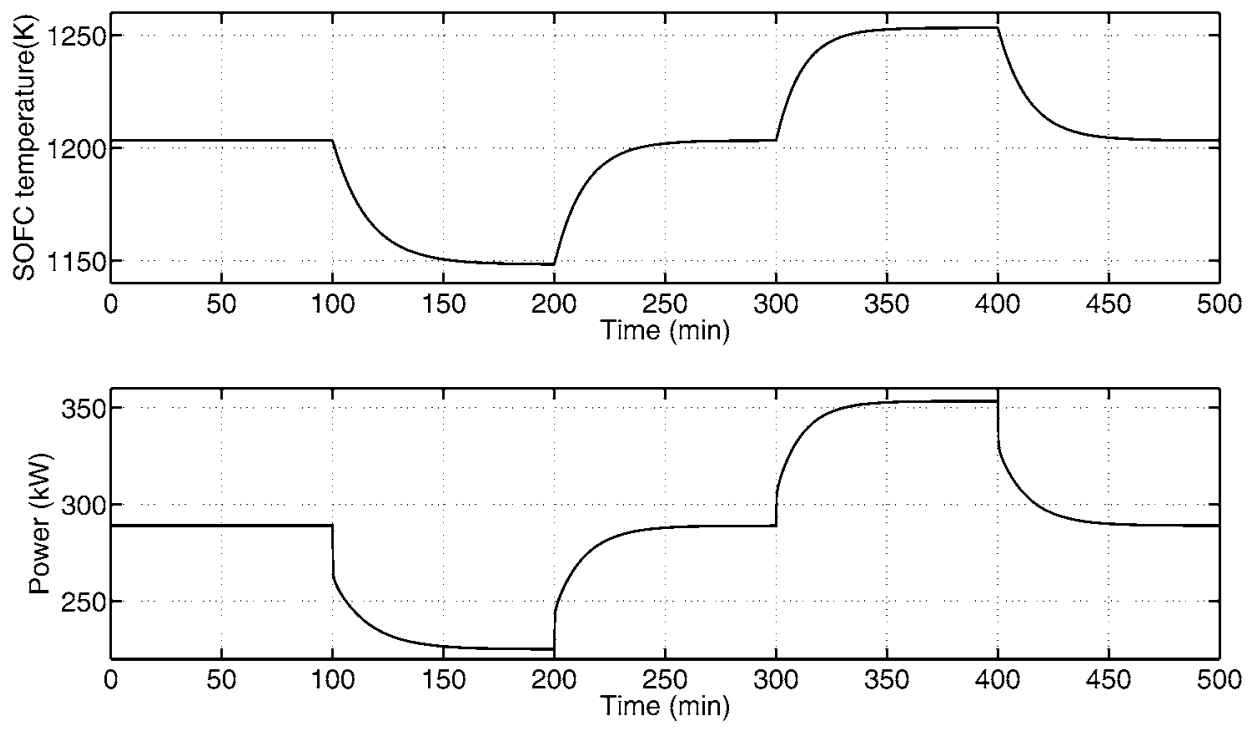

Figure 3. Temperature and power profiles during fuel flow changes. 

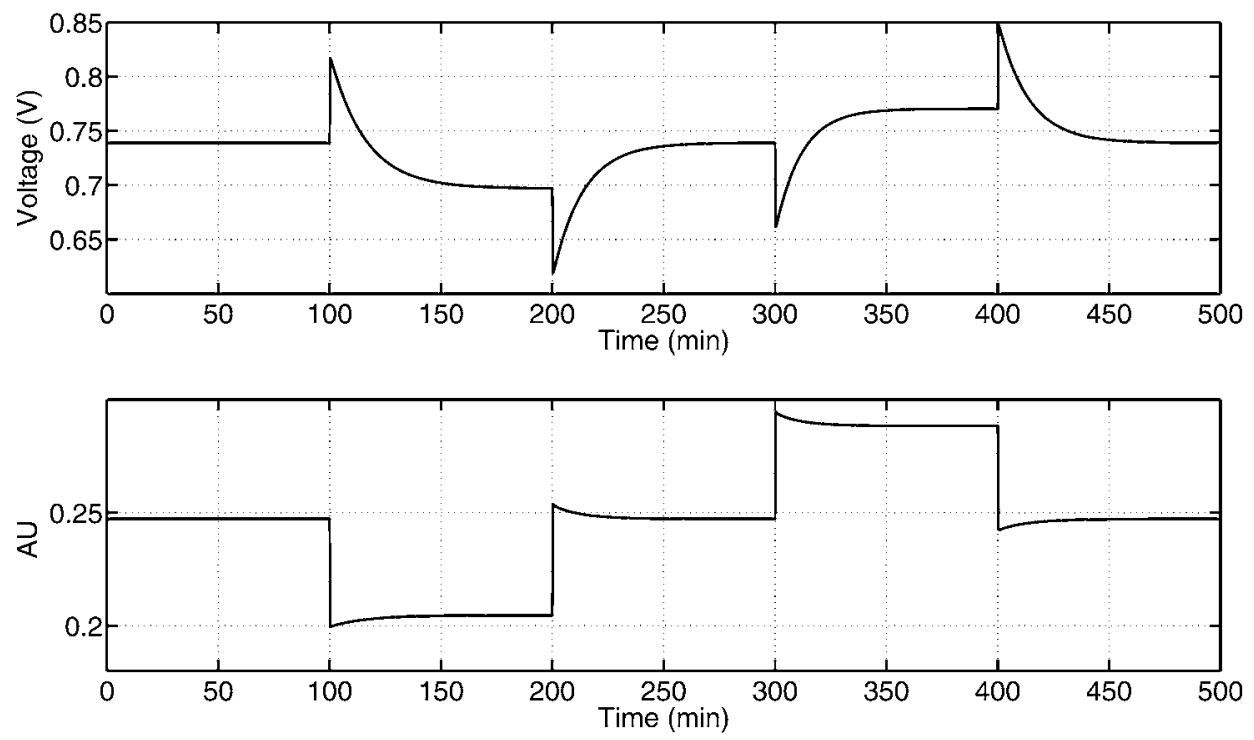

Figure 4. Voltage and AU profiles during fuel flow changes.

Since the electrochemical reaction rate is decreased the amount of air used is lower and hence AU is decreased. At 300 min., the fuel flow rate is increased by $20 \%$ from the nominal value, and the changes in the variables are as expected in the opposite direction to that when fuel flow rate is decreased.

One of the applications of the hybrid system is remote area power supply where instantaneous power changes can be expected. Then the hybrid system has to supply the power according to the need. From the simulation results, note that the dynamics of the power due to changes in fuel flow rate is very slow. Thus, for satisfying the power demand quickly a control system is needed. From the simulation results, it is also clear that when there is a change in fuel flow the SOFC temperature is changing which could cause damage of the SOFC material. The SOFC temperature should not vary beyond certain limits which is a constraint on the SOFC material. To accomplish this, the SOFC temperature is to be controlled by some means when there is a disturbance in the system. In the next section, a preliminary control structure is proposed using Proportional Integral (PI) controllers Skogestad (2005).

\section{Control}

\subsection{Control structure}

The manipulated variables available for control purpose are fuel mass flow, current, and recycle ratio. Some possible choices of controlled variables are total power, SOFC temperature, FU, AU, voltage, Turbine Inlet Temperature (TIT), steam/methane ratio at pre-reformer inlet. In the present case total power, SOFC temperature, FU and steam/ methane ratio are considered as the controlled variables. Steam/methane ratio is controlled by recycle ratio, and FU is controlled by current. Then there are two outputs to be controlled by one input. Hence one more manipulated variable is needed. Three possible choices for the extra input are additional fuel source at combustor, air bypass across SOFC stack, and air blow-off after the compression. After some investigations, air 
Table 4. Simulation details for set point changes

Time Change

120-125 Set point is decreased to $55 \%$ in a ramp

245-250 Set point is increased to $82.5 \%$ in a ramp
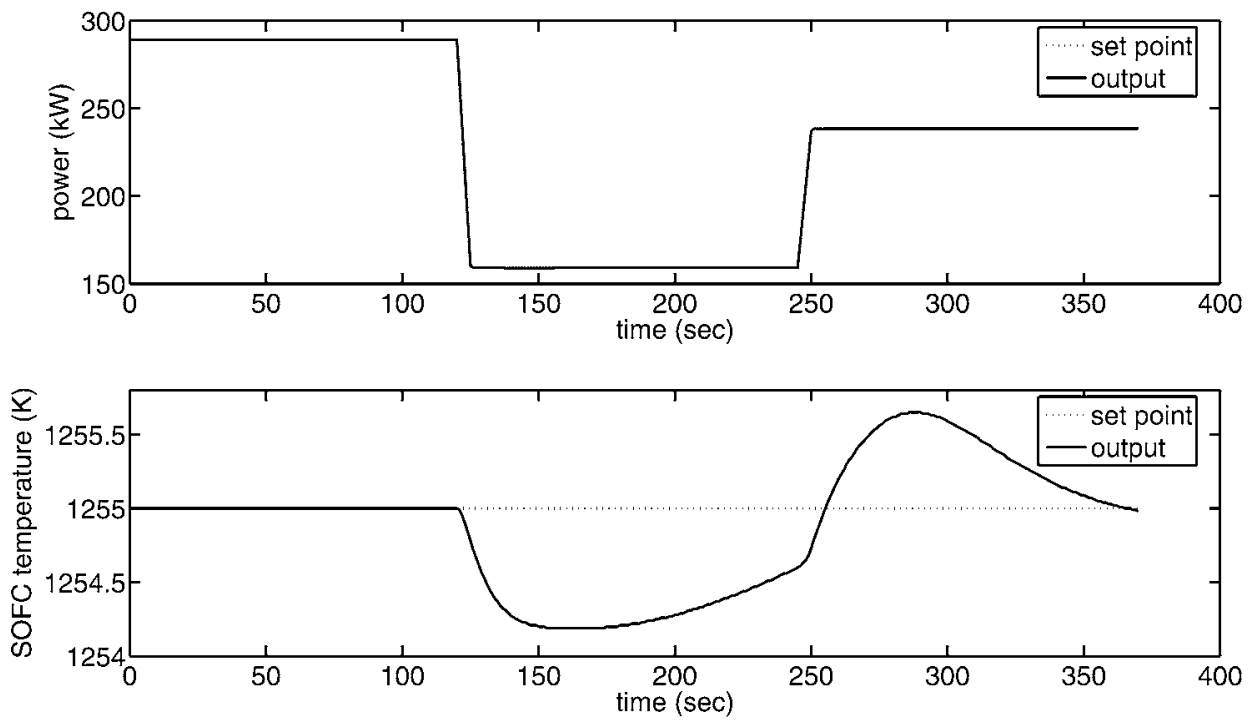

Figure 5. Output power and SOFC temperature during power set point changes.

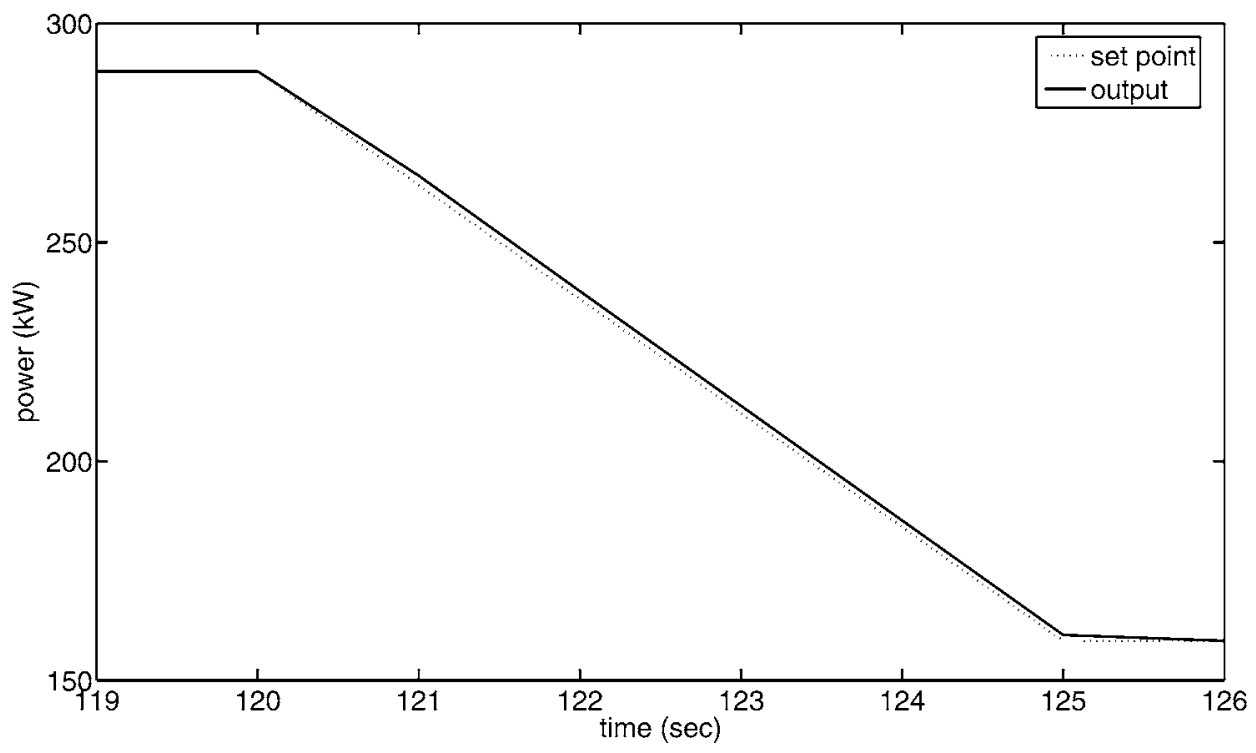

Figure 6. Output power during power set point changes in zoom. 

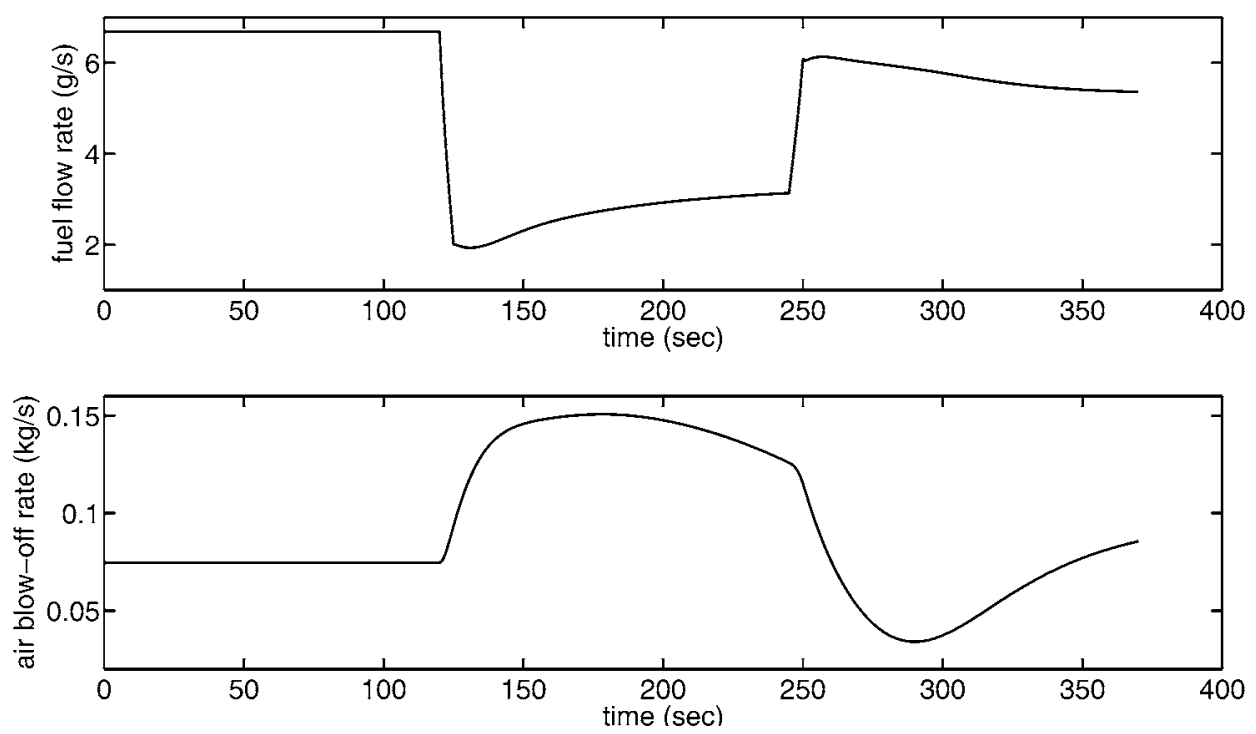

Figure 7. Plant inputs during power set point changes.

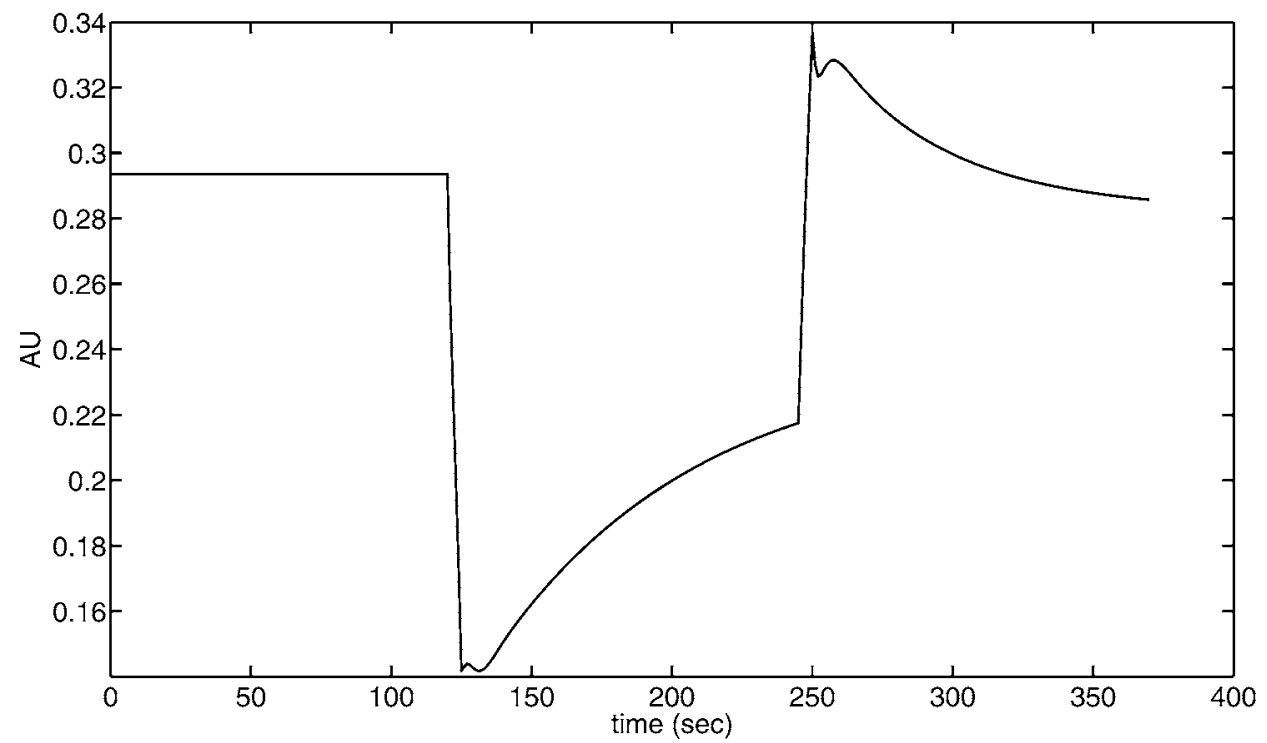

Figure 8. AU profile during power set point changes.

blow-off after the compression is chosen as the static gain from air blow-off to the SOFC temperature is higher compared to the other choices. The control structure is shown in Figure 2.

The non-linear system is linearized at a nominal state and the controller design is done on the resulting linear system. The linear system has 2 inputs and 2 outputs and is a stable system. RGA analysis Skoggestad \& Postlethwaite (1996) is done to select input-output pair for the control structure. It suggests that power is to be controlled by fuel flow and SOFC temperature is to be controlled by air blow-off. Clearly, these pairings are also consistent with our physical understanding of the process. Two SISO 
systems are derived from the system according to the input-output pairs chosen above. A PI controller is designed for each SISO system by following the steps given by Skogestad (2005). Each loop is designed independently, thus resulting in a decentralized PI controller design.

\subsection{Simulation}

The PI controllers designed above for the SISO linear systems are implemented for the non-linear system with the same tuning parameters. Simulations are performed on the non-linear system with set point changes in the power. The details are given in Table 4.

The power output and SOFC temperature profiles for the set point change during the simulation are shown in Figure 5. The power profile zoomed in during the set point decrease is shown in Figure 6. The plant inputs, the fuel mass flow and air blow-off flow profiles are shown in Figure 7.

From the power and SOFC temperature plots it is quite clear that the power from the hybrid system satisfactorily follows the power set point and the SOFC temperature is maintained constant at the reference value. But some other system variables, for example, the AU whose profile is shown in Figure 8, vary too much, which may degrade the SOFC performance.

\section{Conclusions and further work}

A control relevant SOFC-GT hybrid system model is developed. Simulations are performed on the system and some motivation for designing a control structure is presented from the simulation results. A preliminary control structure is proposed using an extra input, air blow-off. PI controllers are designed and simulations with the control structure show that even though the power and temperature are controlled in a desired manner some other system variables of interest show undesirably large deviations. Also, the extra input considered, air blow-off, would decrease the system efficiency. Further work will focus on the design of a more effective control structure which should take care of all the variables of interest for the hybrid system. Furthermore, other process designs (eg. single-shaft GT) will be considered.

\section{Nomenclature}

$\begin{array}{ll}a_{i j} & \text { stoichiometric matrix } \\ A & \text { SOFC surface area } \\ A_{k i}, A_{K^{a d s}} & \text { pre-exp. factors for } k_{i} \\ C^{s} & \text { solid heat capacity } \\ D E N & \text { denominator } \\ E & \text { activation energy } \\ E^{o} & \text { EMF at standard temperature and pressure } \\ E^{O C V} & \text { open circuit voltage } \\ F & \text { Faraday's constant } \\ I & \text { current } \\ k_{2}, k_{3}, k_{4} & \text { rate coefficients for reforming reactions } \\ k_{a n}, k_{c a} & \text { choked flow constants } \\ K_{j} & \text { equilibrium constant for reaction } j \\ K_{i}^{a d s} & \text { adsorption constant for component } i\end{array}$




$\begin{array}{ll}\dot{m} & \text { mass flow rate } \\ n_{r x} & \text { number of reactions } \\ N & \text { number of moles } \\ p & \text { pressure } \\ P & \text { power } \\ r_{j} & \text { reaction rate of reaction } j \\ R & \text { universal gas constant } \\ T & \text { temperature } \\ V_{a n}, V_{c a} & \text { volumes } \\ V & \text { voltage } \\ \Delta \bar{h} & \text { molar specific enthalpy } \\ \Delta \bar{h}^{r x} & \text { molar specific enthalpy change of reaction } \\ \Delta \bar{h}^{a d s} & \text { enthalpy change of adsorption } \\ \delta & \text { shaping factor }\end{array}$

\section{Subscripts and superscripts}

$i$

$j$

an

ca

in

out

rad

cond

\author{
chemical component \\ reaction \\ anode \\ cathode \\ inlet \\ outlet \\ radiation \\ conduction
}

\section{References}

ACHENBACH, E. (1994). Three-dimensional and time-dependent simulation of a planar solid oxide fuel cell stack. Journal of Power Sources.

Chan, S. H., Ho, H. K. \& Tian, Y. (2002). Modelling of a simple hybrid solid oxide fuel cell and gas turbine power plant. Journal of Power Sources.

Chan, S. H., Ho, H. K. \& Tian, Y. (2003). Multi-level modeling of sofc-gas turbine hybrid system. International Journal of Hydrogen Energy.

gPROMS (2004). gPROMS introductory user guide. Process Systems Enterprise Ltd.

Kandepu, R., Imsland, L., Foss, B. A, Stiller, C., Thorud, B. \& Bolland, O. (2005). Control-relevant sofc modeling and model eveluation. Proceedings of ECOS.

Larminie, J. \& Dicks, A. (2003). Fuel Cell Systems Explained. Wiley, England.

Lukas, M. D., Lee, K. Y. \& Ghezel-Ayagh, H. (2001). An explicit dynamic model for direct reforming carbonate fuel cell stack. IEEE Transactions on Energy Conversion, 16(3), September.

Magistri, L., Trasino, F. \& Costamagna, P. (2004). Transient analysis of a solid oxide fuel cell hybrids part a: fuel cell models. Journal of Power Sources.

Padulles, J., Ault, G. W. \& McDonald, J. R. (2000). An integrated sofc dynamic model power systems simulation. Journal of Power Sources, pp. 495-500.

PÅlsson, J., Selimovic, A. \& SJunNesson, L. (2000). Combined solid oxide fuel cell and gas turbine systems for efficient power and heat generation. Journal of Power Sources.

SCHINDEl, J. VAN \& Pistikopoulos, E. N. (1999). Towards the integrated of process design, process control, and process operability: Current status and future trends. In the proceedings of Foundations of Computer-Aided Process Design 99, Breckenridge, Colorado, USA.

SKogeSTAD, S. (2005). Simple analytic rules for model reduction and pid controller tuning. Journal of process control. 
Skogestad, S. \& Postlethwaite, I. (1996). Multivariable feedback control: Analysis and Design. Wiley, USA.

Stiller, C., Thorud, B., Bolland, O., Rambabu, K. \& Imsland, I. (2005). Control strategy for a solid oxide fuel cell and gas turbine hybrid system. Submitted to Journal of Power Sources.

Stiller, C., Thorud, B., Seljebø, S., Mathisen, Ø., Karoliussen, H. \& Bolland, O. (2005). Finite-volume modeling and hybrid-cycle performance of planar and tubular solid oxide fuel cells. Journal of Power Sources, 141, pp. 227-240.

Thомаs, P. (1999). Simulation of Industrial Processes For Control Engineers. Butterworth-Heinemann, Wobourn, MA, USA.

Thorud, B., Stiller, C., Weydahl, T., Bolland, O. \& Karoliussen, H. (2004). Part-load and load change simulation of tubular sofc systems. Proceedings of Fuel Cell Forum, Lucerne, 28 June-2 July.

Xu, J. \& Froment, G. F. (1989). Methane steam reforming, methanation and water-gas shift: I. intrinsic kinetics. AIChE Journal. 